Article

\title{
The Buying Time Argument within the Solar Radiation Management Discourse
}

\author{
Frederike Neuber ${ }^{1, *}$ and Konrad Ott ${ }^{2, *}$ \\ 1 Independent Researcher, Fohlengrund 36, D-18211 Rostock, Germany \\ 2 Department of Environmental Philosophy and Ethics, Christian-Albrechts-University Kiel, Leibnizstr. 6, \\ D-24118 Kiel, Germany \\ * Correspondence: kontakt@frederikeneuber.de (F.N.); ott@philsem.uni-kiel.de (K.O.)
}

Received: 11 June 2020; Accepted: 30 June 2020; Published: 4 July 2020

check for updates

\begin{abstract}
In this article, we will establish a version of the buying time argument (BTA) in favor of Sulphur Aerosol Injection (SAI) Climate Engineering (CE). The idea is not to promote the deployment of such scheme, but rather to present the strongest possible argument pro SAI in order to look at its presuppositions, implications, critical points and uncertainties. In discussing BTA being the only morally sound argument in favor of SAI, the stakes and the overall framework will become visible. If, however, the strongest pro-SAI argument enables us to recognize some major flaws of this technology, this option should be disregarded.
\end{abstract}

Keywords: climate engineering; sulfate aerosol injection (SAI); buying time argument; hubris

\section{Introduction}

The ethical discourse on climate engineering (CE) deals with analytical reconstruction of specific arguments in favor of or against specific CE technologies. Such analyses become parts of the generic CE discourse which has been mapped by [1]. The CE maps are to be embedded in the entire discourse on climate ethics dealing with (a) abatement (reduction of greenhouse gases), (b) adaptation including resettlement programs for climate migrants-however the term "climate migrant" might be defined [2] —and, finally, (c) CE. CE itself can be distinguished into Carbon Dioxide Removal (CDR) and Solar Radiation Management (SRM). A paradigm technology of CDR is BECCS, while a paradigm technology of SRM is Sulfate Aerosol Injection (SAI). SAI is highly contested and requires a detailed and nuanced ethical analysis. The article is devoted to such analysis with respect to the so-called "Buying Time Argument" (BTA) in favor of the deployment of SAI. The article is organized as follows: Section 2 presents some BTA proposals and distinguishes between the emergency-case argument and BTA. It also identifies essential building blocks of the BTA. Section 3 establishes BTA hypothetically by means of deontic logic. By doing so, some crucial requirements (conditionals) of SAI deployment based on BTA become visible. As we argue, establishing BTA comes at the price to recognize conditionals. Section 4 analyses the most advanced instance of BTA and it addresses details of requirements, and Section 5 takes a closer look these requirements. Section 6 presents the main finding of the inquiry and, finally, concludes on BTA. The article is based on a PhD thesis on the BTA [3]. Moreover, it builds on [4-6].

We wish to devote the article to the memory of Steve Rayner.

\section{Building Blocks of BTA}

The original idea of "buying time" stems from Alvin Weinberg [7], who argues that if a society takes a lot of time to solve a specific problem, it might be prudent to buy time by technological means. Even if the problem might be solved within less time in principle (as, in our case, by aggressive immediate abatement of GHG-emissions), buying time might be reasonable if the trade-offs of radical 
solutions look nasty and repugnant. Weinberg's question was "To what extend can social problems be circumvented by reducing them to technological problems?" [7] (p. 42). Weinberg deems the reframing of societal problems as technical ones ("technological fix") to be promising. Societal problems tend to be very complex and solving them might require change in collective behavior and institutions which is hard to achieve. Technological fixes look as clear cut, easy and seemingly effective solutions to some societal problems. The mandatory seatbelt may count as example. Weinberg is, however, well aware about limitations of such technological fixes. Social problems need to be solved by social means eventually, and technological fixes are always a second-best solution. If second-best solutions may have severe side effects or impose new risks upon societies, a fresh look upon first-best solutions, however costly, may become mandatory.

To Weinberg, one beneficial feature of a technological fix is that it may buy more time for social transition. Such time generating quality of technological fixes lies at the heart of the BTA. Buying time, however, is not an end in itself. It serves objectives and, in our case, is seen as a tool within a comprehensive "climate policy portfolio". Questions emerge: What exactly does it mean to 'buy time' within a period of global climate change? Why? From whom? How much? At what costs? For which ends? As we shall see, proponents of BTA give different answers.

One prominent answer to the "why" question is given in terms of "peak shaving", namely that there will be a peak of negative impacts due to climate change in some specific periods in time on a global scale. The critical period of time are decades between 2030 and 2100. This predictive assumption can be backed by many climate impact models. Cumulative GHG emissions have moved the global climate system forward into a highly critical state [8]. There is a bleak outlook of "hothouse Earth" in the longer run, but much loss and damage will occur in the middle run. BTA focusses on the critical middle-term period. There holds a moral obligation to reduce such impacts (some may say loss and damage) which will hit mostly vulnerable groups, especially in the Global South. Beside means of adaptation, the reduction of such adverse impacts requires CE technologies, SAI among them. This strategy can be backed by climate ethics. Holly Jean Buck in her important "After Geoengineering" [9] is the prominent climate ethicists who argues for a temporary pro-poor "humanitarian" SAI based on BTA. Thus, BTA looks as a morally decent and respectable line of reasoning which cannot be falsified by repugnant intuitions against SAI. The authors of [10] investigate and compare different environmental stop-gap measures. Note that the "peak shaving" strategy displays some interesting parallels with the strategy to "flatten the curve" of infections in the COVID-19 epidemic in 2020, although the measures to buy time to flatten the curve are societal ones (as social distancing).

Since the report of the Royal Society [11], the risks of SAI have been pinpointed. No credible author is enthusiastic about SAI. Many authors see the deployment of SAI as conditional. Conditionalities are constraints and requirements which can be warranted in terms of risks, side effects, moral hazard, governance, exit strategies, political misuse ("militarization"), and other lines of reasoning. If one accepts some conditionality, BTA refers in a morally decent way to a conditional and imperfect second-best solution with contested side-effects.

Another, richer answer to the Why? question is found in a 'reducing pressure' framing, pointing at specific time spans (decades) within a long-term global decarbonization. Reducing pressure is one implication of a peak-shaving strategy. Insofar as SAI combats the worst impacts of peak global $\mathrm{CO}_{2}$ emissions, it buys time for different climate approaches that might take longer to show effect, such as mitigation, adaptation or other CDR measures. SAI, as a stop-gap measure with quick results, reduces pressure for implementing other adaptation and decarbonization strategies. It is this reducing pressure framing that seem to lie at the heart of the many versions of buying time or peak-shaving arguments. It is thus a rational, consequentialist argument, that deals with prudent decision making under a scarcity of time.

Note that the concept of adaptation can be used in a broad or in a narrow definition. In a narrow definition, it refers to the adaptation financing schemes which shall help countries of the Global South. In a broad definition, it includes technology diffusion, investment schemes, and capital turnover also 
in the Global North. It is not always clear whether the term "adaptation" is used in a narrow or in a broad way.

The discursive arrangements surrounding BTA suppose time-related concepts, like "time span", "postponement", "delay", or "earlier-than" relations. Thus, a close reflection of BTA requires taking temporal concepts into account (see Section 4). Within the BTA, time is not mere physical time, but "timing" is a moral and political affair.

\subsection{Emergency Situations and BTA}

Peak shaving arguments draw from two different lines of reasoning: (a) being prepared for looming emergency situations and (b) BTA. Both lines of reasoning might be based on a general precautionary principle, but scenarios differ [12]. In a climate emergency situation, SAI might be able to help avert sudden catastrophic climate effects, such as the reaching of several tipping points simultaneously. As the argument goes, one should research and design SAI to arm the future for such emergency situations. The emergency argument is about being well prepared for an emergency, while BTA wishes to avoid such global emergencies preemptively. The recent literature rejects the "emergency" framing completely and sharply $[13,14]$, since it is scientifically flawed and politically dangerous.

In an emergency, SAI would not be much help for reducing climate impacts running out of control. Once tipping points have been reached, SAI will not be able to reverse these effects. Thus, it is not scientifically credible that SAI will be helpful in an "actual" emergency situation. Secondly, an emergency situation is not just 'out there', but must be declared by political authorities. There is no democratic authority on a global scale being entitled to declare a global climate emergency. Moreover, it is a common trait of authoritarian policies to declare emergency situations in order to expand authoritarian power. Remember Carl Schmitt, who stated that "Sovereign is he who decides on the exception" [15] (p. 36). The legal status and political background of an emergency situation may threaten democratic structures. If so, there is a high risk of political misuse of the emergency framing. The emergency framing may fall prey to the militarization and securitization of SAI [16]. It does not come at surprise that SAI to be deployed in an emergency situation might be substantiated via the just war theory [17]. Hence, the emergency situation argument fails on scientific ground and it displays repugnant flaws on political grounds. If one discards the emergency framing, as we do, BTA is the "last man standing" in favor of SAI within the CE discourse.

\subsection{Some BTA Proposals}

BTA advocates a preventive deployment to avoid adverse impacts in the first place. The general BTA idea has been outlined nicely by Horton in 2015:

"The most common alternative [to the emergency framing-FN/KO], known as 'peak shaving', would entail application of SAI or some other type of solar geoengineering to reduce the worst effects of peak GHG emissions while implementing an ambitious program of mitigation and adaptation. One variant of peak shaving would involve a gradual ramp-up of solar geoengineering until a modest plateau is reached; as emissions declined, so too would injections of stratospheric aerosols. Another potential approach would utilize SRM on a regional scale, for example in the Arctic, in order to address specific, localized damages from climate change." (Horton 2015) [14] (p. 4f).

"With the help of SAI, the worst impacts of temperature rise could be averted on global or regional scales (peak shaving). It is stated that SAI should be limited in time and should be related to long-term abatement trajectories. The 'while' indicates that abatement must be done in parallel. SAI technologies, then, might "be used as a stop-gap measure to buy time for a societal transformation to a carbon-free economy, shaving off the worst effects of climate change along the way" (Schäfer 2014) [18] (p. 5). 
"An optimal outcome would seem to be that mitigation can be accomplished relatively rapidly and relatively easily, such that geoengineering might need to be implemented for only several decades in order to shave off the peak change in climate and increase the likelihood that the most adverse and irreversible environmental and societal consequences will not be triggered." (MacCracken 2009) [19] (p. 11).

Here, the time span of SAI is specified to some decades. The Royal Society (2011) formulates the BTA similarly:

"The length of time required to phase out fossil fuels, and to modify the various global human systems contributing to climate change, may be longer than the time available to avoid serious adverse impacts. In this case, SRM might have the potential to temporarily stabilize the global temperature and its associated effects, while providing time to reduce GHG emissions" [11] (p. 19).

Several authors have taken the same route of argument. "A popular framing is that sunlight reflection could 'buy time' for decarbonizing the economy and allowing greenhouse gas concentrations to stabilize and then come down." (Lenton 2013) [20] (p. 2). Note that scientists, as Timothy Lenton, who are critical of emergency framing, see BTA differently. Another instance of BTA is this:

"Some geoengineering measures appear to offer humanity the ability to shave the peaks off $\mathrm{CO} 2$ driven emissions and avoid tipping points. Wigley (2006) argues that sulphate particle injection might be used to 'buy time' in reducing $\mathrm{CO} 2$ emissions. This potential to shave peaks would go some way to addressing the concern voiced by some that temperature rises over the next century may exceed irreversible tipping elements' in the climate system leading to drastic changes with potentially catastrophic impacts on human and natural systems." (Rayner 2013) [21] (p. 8).

These collected quotes are paradigmatic, as they indicate that BTA circles around the same basic idea. Ideas, however, always rest on presuppositions; they bring about conceptual commitments, and they have implications. Following Hintikka [22] and Brandom [23], we regard the analysis of presuppositions, implications, and commitments as being one crucial task of philosophical inquiry. Such inquiry is now bestowed on the BTA.

BTA assumes that unmitigated climate change poses paramount risks to the entire planet. Thus, BTA is incoherent with climate change denial. BT strategies are temporary middle-range strategies being connected both to long-term abatement and adaptation strategies. This is to say that SAI should be supplementary to abatement, but should not be seen as a substitute. If such relation is adopted, a crucial requirement ("complementarity only") has been identified. Prominent proponents of BTA accept such conditions (Section 4). Incoherence with climate change denials and the complementarity requirement are two basic suppositions of BTA.

Here, however, the trade-off argument (TOA) comes into play, which is often defined as "moral hazard" (see [4]). If SAI will be deployed under the intention to buy time for adaptation and shave peaks, it might happen that abatement efforts are reduced because many influential agents (industries, politicians, consumers, investors) may misinterpret SAI as a substitute abatement [24]. The intentions of BTA proponents may differ widely from the misperceptions and misinterpretations of SAI research and deployment. If so, BTA may rest on heroic underlying assumptions of commonly shared intentionality to justify the performance of SAI. Ott [5] and Surprise [16] have cast doubts on such assumptions pointing to real-world interests instead. We will return to this point in the final part of this manuscript, Section 6.

There is broad agreement that SAI technologies might not represent a ready-made, easy-to-control tool that could be ramped up and down in a relatively simple manner. All authors agree that SAI would need proper governance. If so, SAI is conditional to proper governance schemes whose authorities 
have some democratic legitimacy to decide both on deployment and exit-strategies. We will address this crucial point in Sections 4 and 5.

\subsection{Temporary Deployment Only}

One central assumption of the BTA is the prospect of society developing towards a low-carbon economy. If production and consumption start being carbon neutral, $\mathrm{CO}_{2}$ emissions also will decline toward zero. If so, SAI deployment might no longer be needed. The underlying assumption of the inevitable transition to a low-carbon society implies that CE deployment will be temporary only. BTA rests on the promise that there will be soon a time after SAI. For example, "Geoengineering might need to be implemented for only several decades" [19] (p. 11); "At least among policy makers, nobody believes that geoengineering offers anything but a relatively short stopgap to buy time for other action" [25] (p. 2). We are not sure about policy makers, but like to restate Bunzl's claim with respect to CE scholarship. This, indeed, is the very meaning of a stopgap: being limited in time. "Temporal only" and "soon" must be, of course, specified to time scales, but logically it implies a contrast to "without end". In any case, the "temporarily" condition refers to time-related concepts.

This "finitude" assumption counts as a crucial conditional. Its details are, however, full of unresolved questions. Figure 1 presents the finitude condition as related to $\mathrm{CO}_{2}$ emissions.

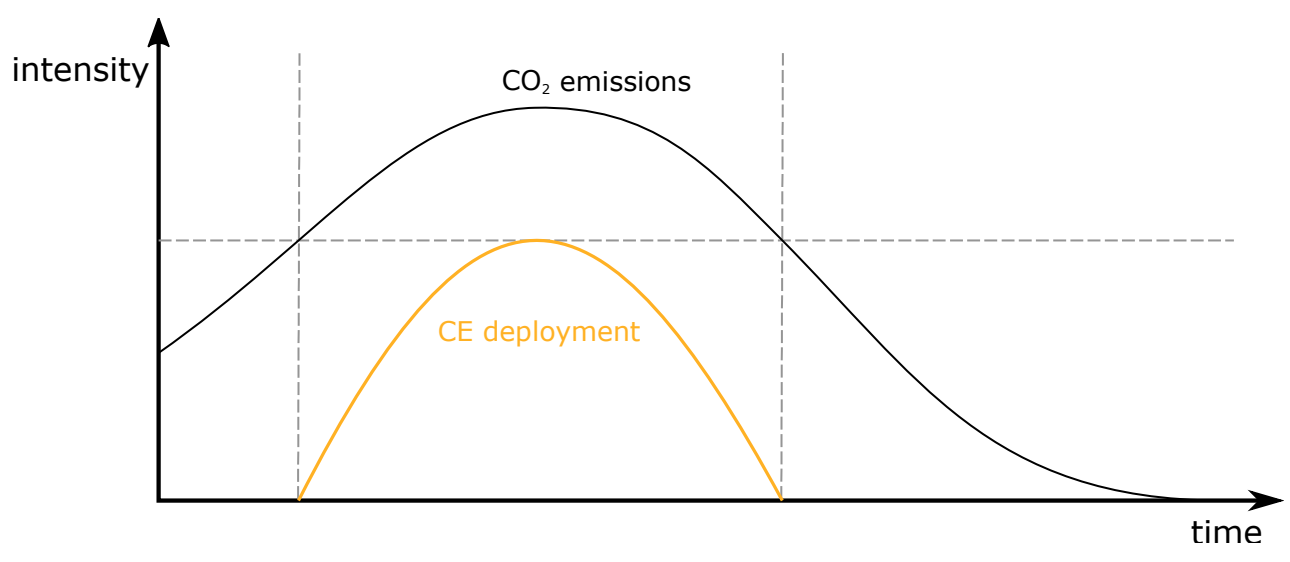

Figure 1. Simplified peak shaving/buying time deployment. The orange line indicates a temporary, modest deployment of SAI that declines parallel to $\mathrm{CO} 2$ emissions.

This simple idea and the above figure are, however, spurious. They assume that the worst climate impacts coincide with the peak of GHG emission: "reduce the worst effects of peak GHG emissions" [14] (p. 5) (emphasis added FN/KO). However, climate impacts result from the cumulative GHG concentration in the atmosphere, not from annual emissions. Since the concentration of atmospheric $\mathrm{CO} 2$ concentrations will not go down as emissions are curbed, dangerous climate impacts may occur even after we have curbed GHG emissions aggressively. The latest results of [26] point to another direction. The authors show that warming does not continue after net-zero emissions have been reached. The relation between global warming and global emissions seems to be rather tight, which does not mean, however, that the impacts of global warming cease as soon as net emissions reach zero. If so, BTA must be relative to presumed impacts, not to emissions. The notion to use SAI until our GHG emissions go down is, therefore, misleading. CE, as a peak-shaving measure, would have to be used until the impacts of GHG concentrations go down which, as indicated, might considerably lag behind our mitigation efforts. This clearly affects the "temporariness" condition since SAI must be prolonged.

It might be argued that this is a rather trivial point since one could easily advance a peak-shaving argument that relates to peak concentrations instead of emissions. We argue, however, that we may face a risk within the "finitude" conditional. Prolongation bears the risk of unlimited SAI. As we 
shall see in more detail in Section 4, BTA is conditional to "exit strategies.". BTA rests essentially on the assumptions that there are viable exit strategies. This means, that SAI should not turn out to become a "lock-in" technology. If BTA is related to cumulative GHG concentrations, the anticipated duration of SAI deployment would rise significantly. It clearly makes a moral and political difference if peak-shaving technologies must be deployed over generations, since many additional assumptions must be made in terms of political stability, international cooperation, cost sharing, legal governance schemes, social cohesion, peace and the like. If there is anything to learn from history, then one may have learned how fragile civilizations may become. If so, long-term peak shaving SAI has to invest much silent trust in the political boundary conditions of technologies.

Clearly, emissions influence the atmospheric GHG concentrations. Insufficient abatement might also inflate the time span even for a moderate time-buying deployment [19]. There might be always some reasons to prolong SAI deployment until it turns out to be the normal state of affairs. There is a risk in any BT scenario that SAI continues without definite end. The "temporarily" conditional should not be taken as a given. Any specification in terms of "some decades only" is nothing but a promise being based on some optimism with respect to global abatement policies. Here, a contradiction occurs if the need for SAI is based on pessimism with respect to abatement policies, while the "temporarily" conditional is based on optimism.

In any case, in order to make the BTA as strong as possible, the relation between emissions, concentration, abatement efforts and rise in global mean temperature must be made as transparent as possible. We hope to do so by specifying the deployment scenarios with regards to different emission pathways (Section 4).

\subsection{BTA and the Costs of Abatement}

It is a crucial presupposition of BTA that transition to a global low-carbon society should happen anyway. The inevitable transition towards carbon-free production and consumption should arguably come at the lowest possible social and economic opportunity costs. This is part of the "efficiency" rationale that David Keith has provided [27]. Zürn et al. argue along the same line in favor of prudent SAI deployment, partially because of its cost effectiveness, stating that, "Due to the high costs arising from the necessary transition to a carbon neutral economy, all options that could contribute to reducing the costs of this transition should be explored". [28] (p. 6).

In a similar vein, Wigley [29] has offered a calculation of a policy mix consisting of abatement and $\mathrm{CE}$ that proves to be less costly than rapid emission abatement exclusively: "A combined mitigation/geoengineering approach to climate stabilization has a number of advantages over either alternative used separately. A relatively modest geoengineering investment ( ... ) could reduce the economic and technological burden on mitigation substantially, by deferring the need for immediate or near-future cuts in CO2 emissions" [29] (p. 454). As important as mitigation might be, an additional CE deployment could "provide additional time to address the economic and technological challenges faced by a mitigation-only approach" [29] (p. 452). Since some CE technologies could arguably be launched slowly and as easily be tapered off again, buying time could be a form of adjustment to correct and support the progress of abatement.

"Even absent any climate emergency, CE can be used as part of a low-cost inter-temporal climate response by deploying it incrementally to shave the near-term peak of global heating that would occur this century even with aggressive emission cuts. Such an incremental deployment, phased in then out over a century or so, could reduce near-term climate disruption and associated risks, thereby buying time and allowing emission cuts and adaptation measures to be made in an orderly program of technology deployment and capital turnover, at much lower cost and disruption than under more rapid deployment" [30] (p. 318). 
Note, that Parson and Ernst implicitly prolong the time scale of SAI deployment to "a century or so". Here, buying time refers to capital turnover and estimates of opportunity costs. We leave the point of capital turnover aside since this opens the door into the political economy of SAI [5]. We will not follow the line of reasoning that the real "loss" to be avoided by SAI is the loss in the relative value of capital stocks in fossil fuel intensive economic branches [5].

BTA supposes a management of an inevitable decarbonization of society while reducing its costs. Catastrophic climate change would likely unfold over a number of centuries, but avoiding it will require a technological revolution, and "geoengineering might help to 'buy time' to develop and diffuse these new technologies" [31] (p. 50). Here, BTA refers to diffusion of low-carbon technologies. $\mathrm{CE}$ technologies might render the transition easier, less costly or less abrupt, thereby taking some pressure off immediate choices of action. This is the climate economic dimension of BTA which deserves some additional reflection.

There are two approaches in climate economics. The mainstream approach is oriented towards efficient ("optimal") solutions. Under this approach, SAI is an attractive tool. As has been argued elsewhere [32,33], this approach is full of underlying moral assumptions, as rate of discount, value of a statistical life, monetization of ecosystem services, rate of substitution, aggregation of utility functions, etc. If so, the idea to calculate a global utility function for mankind over a century is illusionary at best, and ideological at worst. This is true a fortiori, if the calculation has to move within a complex dynamic portfolio being composed out of mitigation, adaptation, CDR, and SRM. Thus, we discard this "optimality" approach on theoretical grounds. On more empirical grounds, the costs of SAI deployment may be underrated by its proponents [34]. Interestingly, recent economic models indicate that global economic benefits of SAI are rather small and may even become negative under an RCP4.5 scenario [35].

The second economic approach is conceived as the standard price approach. A normative yardstick is adopted as supreme standard (or objective). The Paris goal of "well below $2{ }^{\circ} \mathrm{C}$ " can be regarded as such a standard, as it specifies the objective of Art. 2 of the United Nations Framework Convention on Climate Change (UNFCCC) to avoid dangerous anthropogenic interference with climate system. Given such a standard, climate economics may assess how to reach such goal efficiently. BTA, then, becomes part of such "least cost planning". The negative peak of aggressive GHG abatement might be a global recession, but prudent economics buys time in order to flatten the curve in terms of loss of global GDP growth. If so, a buying time deployment of SAI might aim at (at least) two different objectives: On the one hand, SAI shaves the peak of negative impacts, while on the other hand, it optimizes the distribution of opportunity costs of transition towards low-carbon economies.

Neuber [3] has distinguished two types of climate goals: primary climate goals, that aim at preventing climate tipping points, and secondary climate goals, that focus on reducing pressure for adaptation and mitigation. Primary climate goals can arguably be backed by general climate ethical considerations, whereas secondary climate goals lie within the scope of economic rationale, which, of course make some normative assumptions. Reducing the social, economic and civil costs of climate policies is a worthwhile objective and can reasonably be put into play alongside primary climate goals.

Hence, a time-buying deployment of SAI will address both the primary and the secondary climate goal. Time will be bought for capital turnover, technology diffusion, adaptation, etc. Such perspective allows placing a morally motivated "peak shaving" into the foreground of BTA under a perspective of "least cost planning".

The costs to be avoided are (a) moral costs in terms of loss and damage, and (b) economic costs in terms of capital turnover, loss of jobs, loss of growth rates and the like. Such a two-fold perspective of avoiding loss and damage and curb the opportunity costs of transition even strengthen the BTA. 
To summarize this section, six essential elements ("building blocks") of the BTA have been identified on a reflective reading of BTA proposals:

1. Primary climate goal-Averting dangerous climate impacts by "humanitarian" peak shaving;

2. Secondary climate goal-Reducing pressure of abatement and/or adaptation, "least cost planning";

3. Complementarity (amendment), not substitution to emission abatement;

4. Proper governance;

5. Temporary deployment only, realistic exit-strategy.

Of course, those requirements can be contested (for example [36]). We believe them to be the core elements of the BTA. From those building blocks, we will now forge a comprehensive BTA that holds logically and suffices morally.

\section{Establishing the BTA}

In essence, BTA is a consequentialist argument: a specific means should be used in order to realize a desired end. For the BTA, this consequentialist principle reads as follows: a certain climate policy mix should be adopted in order to reach a pre-defined climate goal (at minimal cost). SAI is a permissible asset in such mix. The deontic logic of this argument is simple: An action (A) is permissible (or even mandatory), if specific requirements $(\mathrm{R})$ (= conditions) are met. A is forbidden if the requirements are not fulfilled. If SAI might be mandatory as "peak shaving" but forbidden because the requirements cannot be fulfilled, we might face a dilemma. An actual dilemma would require complete different deontic analysis. For the sake of argument, we focus on the permission of SAI. Correlations between the deontic status of permissible actions and the fulfillment of requirements have a simple logical form: $r_{1}{ }^{\wedge} r_{2}{ }^{\wedge} \ldots{ }^{\wedge} r_{n} \rightarrow \diamond A$, where $r$ denotes a requirement and $A$ is the action in question. The deontic status is denoted via the symbol $\diamond$. This deontic scheme underlies the BTA as well.

Six requirements (conditionals, restrictions) have been extracted from in the previous section. These special buying time requirements shape the buying time principle (idea), which underlies the buying time argument. If a climate policy mix incorporates the BT requirements, it can be said to be a permissible buying time deployment. SAI being based on the BTA, then, counts as legitimate asset in an overall climate portfolio. In order to establish such BTA, a placeholder must be introduced: Placeholder O stands for comprehensive climate portfolio, which SAI is a part of. Equipped with such prerequisites we can now establish the semi-formal Buying Time Argument:

\section{Buying Time Principle (BTP)}

If: i. option O leads to a desired climate goal and is beneficial in doing so, ii. option O only reckons with finite SAI deployment, iii. SAI in O does not lead to less mitigation of deploying agent A compared to mitigation in $\mathrm{O}$ without SAI (The stumbling block in this requirement is the "deploying agent $\mathrm{A}$ ". Since the BTA seeks to justify deployment of SAI, and deployment presupposes someone who is deploying, the requirements indirectly always refer to an agent. Regarding mitigation, climate ethics distinguishes rights to emit-in states of the global south, subsistence emissions are always morally legitimate [36], while luxury emissions in developed nations are not. If a nation decides to deploy SAI, it must prove that it will not use SAI as a free ticket to balance its luxury emissions. It is possible that the "no abatement requirement" must be sharpened even stronger to the deploying agent.), iv. there is no option $\mathrm{O}^{\prime}$ which is better than $\mathrm{O}$, v. there are no general moral constraints to option $\mathrm{O}$; then option O should be adopted. 


\section{Buying Time Argument (BT Argument)}

BT1 If (i) option O leads to a desired climate goal and is beneficial in doing so, (ii) option O only reckons with finite SAI deployment, (iii) SAI in O does not lead to less mitigation of deploying agent $\mathrm{A}$ compared to mitigation in O without SAI, (iv) there is no option $\mathrm{O}^{\prime}$ which leads to the desired climate goal and which is better than $\mathrm{O},(\mathrm{v})$ there are no general moral constraints to option $\mathrm{O}$; then option $\mathrm{O}$ should be adopted.

BT2 The climate goal is indeed desirable (desirability).

BT3 Option O leads to desirable climate goal (effectiveness).

BT4 Option O only allows for finite CE deployment (temporariness, finitude, or exit strategy).

BT5 CE in O does not lead to less mitigation of deploying agent A compared to mitigation in $\mathrm{O}$ without CE (no-impediment thesis or supplementary-only thesis).

BT6 There is no option $\mathrm{O}^{\prime}$ which is finite and which leads to the desired climate goal and which is better than $\mathrm{O}$ (no better option).

BT7 There are no general moral constraints to Option $\mathrm{O}$ (morality including governance requirements).

BT8 THUS Option O might (or, perhaps, should) be adopted.

We hold that the basic characteristics of the BTA are captured quite adequately in this formulation of the argument. The BT principle entails six essential requirements. Each requirement states a necessary condition; together, they are sufficient for SAI deployment to be morally acceptable and permissible. Since we wish to keep the argument structurally as simple as possible, we see the governance conditional as part of BT7. The next section will focus on the instantiation of the requirements and the conditions of their fulfillment. As we shall see in detail, there are many risks that the requirements remain unfulfilled. If perfect fulfillment of all requirements may be seen as the ideal standard to perform SAI on the grounds of BTA, one may focus the debate to situations in which requirements are only fulfilled partially, but not perfectly. This distinction is made transparent if someone deviates from the condition of the perfect fulfillment of requirements and wishes to rely SAI on partial fulfillment only. In any case, the logic structure enables to distinguish between perfect and imperfect instances of BTA with respect to requirement. Here, one can see the practical sense of logic.

\section{A Case Study of a BTA Instance}

Due to the generic status of the argument given in the previous section, there are placeholders involved in order to discuss the specific requirements and their fulfillment. As encouraged in the previous section, we will have a closer look on one SAI scenario which counts as an instantiation for the placeholder $\mathrm{O}$ (or, to be more precise, for a climate engineering strategy within policy option $\mathrm{O}$ ). There are, of course, many SAI scenarios to be found in the literature (overview in [37]). We select and focus one specific scenario, since it is specifically shaped to showcase a buying time instantiation of option $\mathrm{O}$ (though not under this nomenclature).

This scenario has been proposed by David Keith and MacMartin and their colleagues [38,39]. These authors incorporate the idea of arguing on a case-by-case basis, stating that "One cannot meaningfully evaluate solar geoengineering without a scenario for its implementation." [39] (p. 201). This scenario resonates perfectly with our analysis which asks for a case specific inquiry of the empirical premises of the BT argument. Thus, the SAI scenario of Keith and his colleagues will function as paradigm case study for the further evaluation of the BTA. 
In their proposal, SAI is used in order to reduce the rate of global temperature change for a given emission trajectory, rather than stop the temperature increase altogether. This scenario is an excellent example for the BTA, for it is designed specifically in accordance with the buying time and peak-shaving approach: "At a minimum, introducing [the proposed SAI scenario] would increase the amount of time to both learn and adapt; by reducing the needed rate for adaptation, it could reduce costs of adaptation" [38] (p. 2). Here, the cost-reduction perspective ("least cost planning") is evident and specified in terms of adaptation (in a broader sense, as we suppose).

The temperature increase in the 21st century will have, even under optimistic mitigation assumptions, a severe influence on life on earth. It is not only the absolute change in global mean temperature, which catalyzes dangerous climate events, but also the rate of warming. The frequency and strength of some climate events are determined by the warming rate. A speedy temperature increase will make adaptation even more difficult [38].

SAI could limit the rate of global temperature rise. This way, the authors argue that SAI could buy time for adaptation measures, writing that, "In particular, using SRM to limit the rate of temperature change would provide more time for both ecosystems and human systems to adapt to climate changes [38] (p. 11). Buying time now points to adaptation capabilities, broadly conceived. The scenario is designed to meet specific criteria: It has to be temporary, moderate and responsive. These are the normative requirements that guide the scenario setup. They correspond with the requirements being adopted in the previous sections.

The technology envisaged by the authors is SAI. Authors assume the radiative forcing of one million tons of sulfur (MtS) to be $0.6-0.8 \mathrm{Wm}-2$. For a given $\mathrm{RCP}$, the scenario targets at cutting the rate of change of the respective radiative forcing in half. This suggests that the choice of a certain $\mathrm{RCP}$ is decisive for the scenario. "The choice of emissions trajectory has a profound influence over the magnitude and duration of geoengineering required to limit the rate of change of global mean temperature" [38] (p. 5). For the main part of their investigation and for illustrative purpose, the authors assume RCP4.5 and they calculate the amount of injected sulfur accordingly. In the RCP4.5 pathway, injection would start with $0.035 \mathrm{MtS}$ per year and would increase steadily in the first decade by the same amount. After 10 years, the yearly injection would amount to $0.35 \mathrm{MtS}$. The rate of injection would be adjusted in order to steady the rate of temperature change (see picture below, second panel).

As Figure 2 shows, the point in time at which temperature reaches a certain degree above pre-industrial level is delayed for several years, if SAI is used to limit the rate of temperature change. Using a different approach, the authors determine the amount of SAI in accordance with a steady warming rate of $0.1{ }^{\circ} \mathrm{C}$ per decade (instead of cutting warming rate in half, as in [39]). For RCP4.5, the length of required SAI deployment would have to be 160 years, if SAI is used to limit temperature change to $0.1^{\circ} \mathrm{C}$ per decade, as Figures 3 and 4 show.

For other RCPs, Figure 5 indicates the required timeframe and intensity of SAI schemes for varying temperature goals. If SAI is used to constrain temperature rise to $0.0^{\circ} \mathrm{C}$, that is to maintain current temperature, for all RCPs but RCP2.6, the finitude of the CE scheme is not given at all.

"It is important to repeat that SAI in this scenario would not be used to tackle absolute temperature change: (...) it [temporary SRM deployment, FN/KO] would not address problems such as temperature-dependent tipping point thresholds" [38] (p. 2). SAI would only account for reducing the rate of change for a given temperature rise, not its magnitude. In this setup, abatement remains the main driver to limit global temperature rise. Accordingly, it is only emission abatement which could possibly lead to the stabilization of global mean temperature at well below $2{ }^{\circ} \mathrm{C}$ above pre-industrial level. Thus, the supplementary requirement has been adopted. 

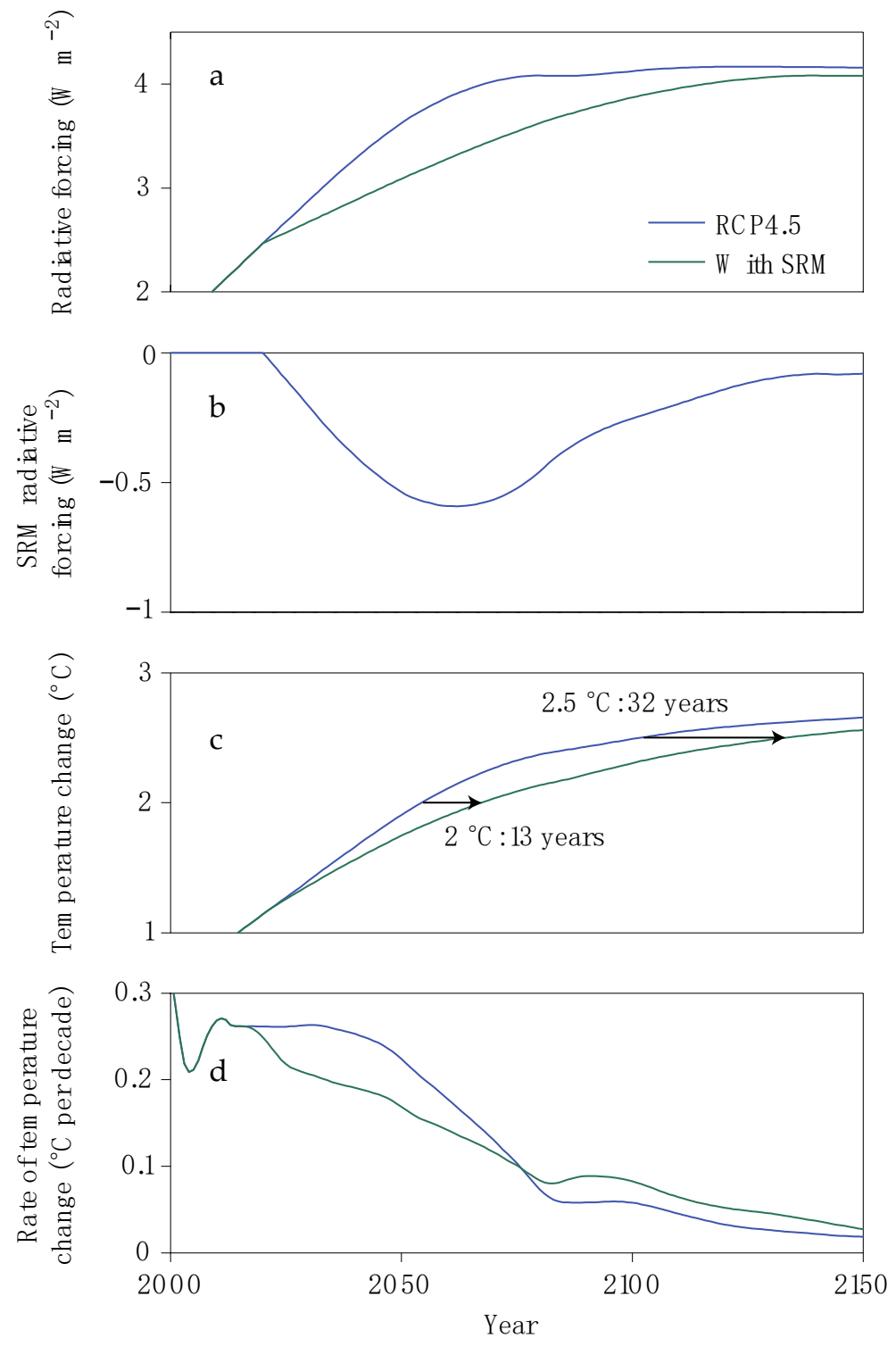

Figure 2. The top panel (a) shows the total radiative forcing for RCP4.5, and a radiative forcing profile in which the rate of change is halved. The second panel (b) indicates the suggested SAI (SRM) profile. The effect on global mean temperature is shown in the third panel (c), indicating the time benefit, and the corresponding injection rates per decade are shown in the last panel (d) (source: [39]).

This scenario does not frame SAI as a substitute for abatement, since both SAI and abatement are concerned with different aspects of global climate change. While the former addresses the rate of change, the latter influences its quantity. The absolute temperature change is still determined by abatement efforts, and SAI would be used only supplementary and temporarily to reduce the rate at which this change is to come about. As introduced above, there are primary and secondary climate goals, and this scenario clearly frames SAI for the secondary purpose of reducing the rate of change in order to reduce pressure. In this scenario, SAI does not reduce the dire need for drastic emission cuts-it instead points out what additional help SAI could generate. This is a great advantage of the scenario, since it does not run afoul of being a "cheap techno-fix" or posing a dilemma fo future generations [40]. Moreover, the no-impediment requirement becomes at least plausible in this scenario.

If, moreover, a mitigation pathway like the RCP2.6 is assumed, the well below $2{ }^{\circ} \mathrm{C}$ target might be reached with abatement efforts only, while SAI would primarily address the secondary climate goal of reducing adaptation pressure. This shift of the BTA to the realm of adaptation is not trivial. 

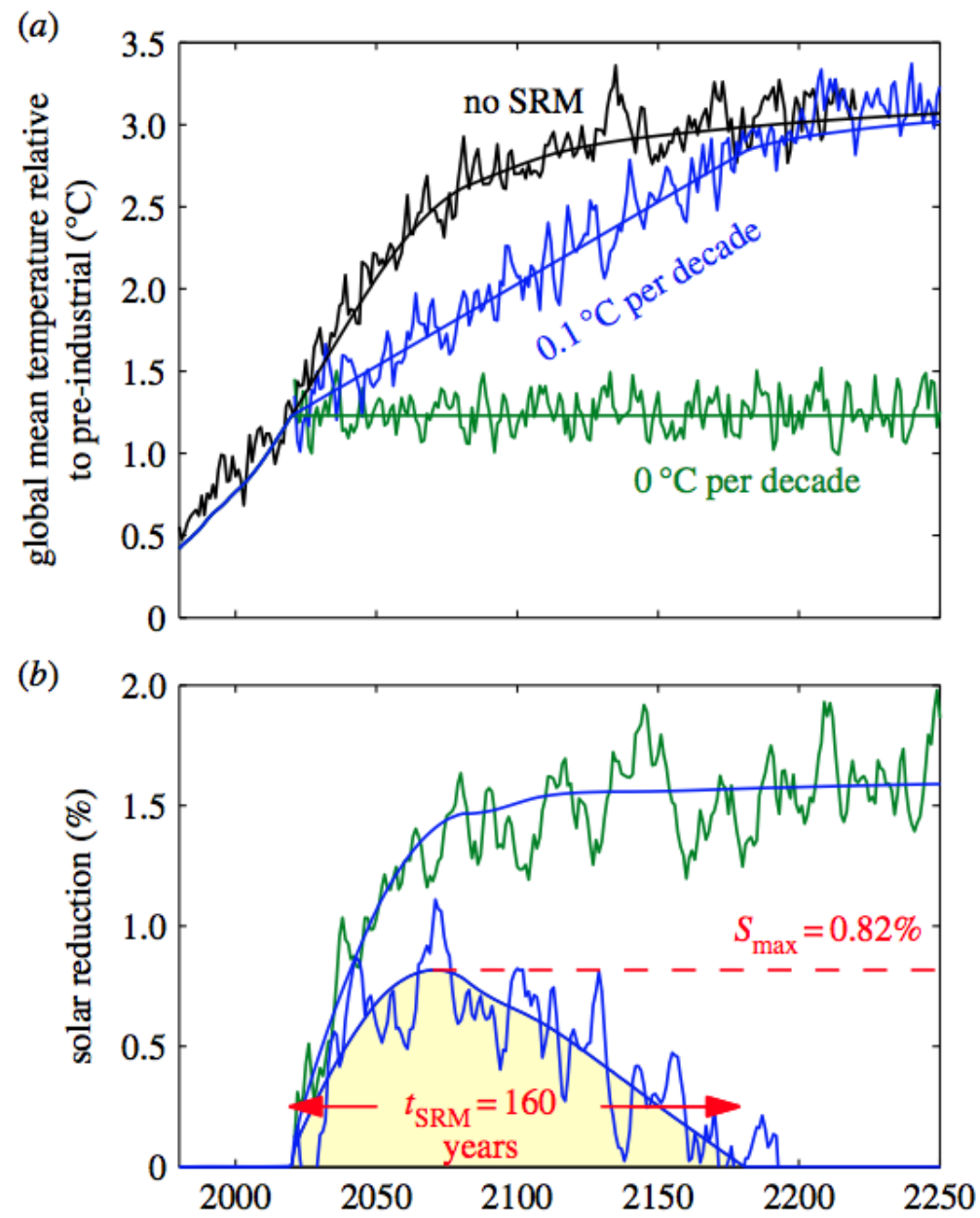

Figure 3. The top panel (a) shows SAI (SRM) being used for either maintaining constant global mean temperature $\left(0{ }^{\circ} \mathrm{C}\right.$ per decade) starting in 2020 or limiting the rate of change to $0.1{ }^{\circ} \mathrm{C}$ per decade for an RCP4.5 pathway. Panel (b) shows the corresponding solar reduction potential of SRM as well as the length of time over which SAI (SRM) would have to be deployed (source: [38], online version in color).

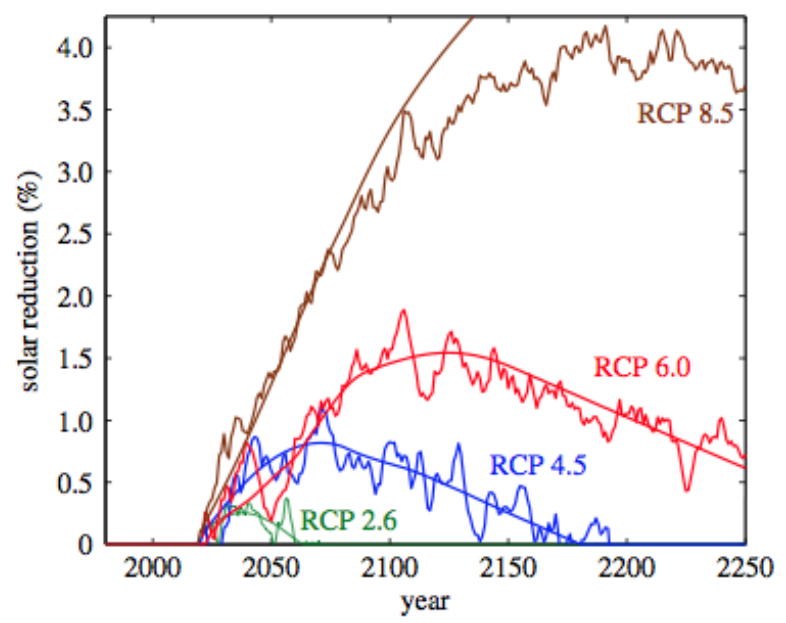

Figure 4. Comparison of the solar reductions required to maintain a $0.1{ }^{\circ} \mathrm{C}$ per-decade rate of temperature change for different emission pathways (source: [38]). 

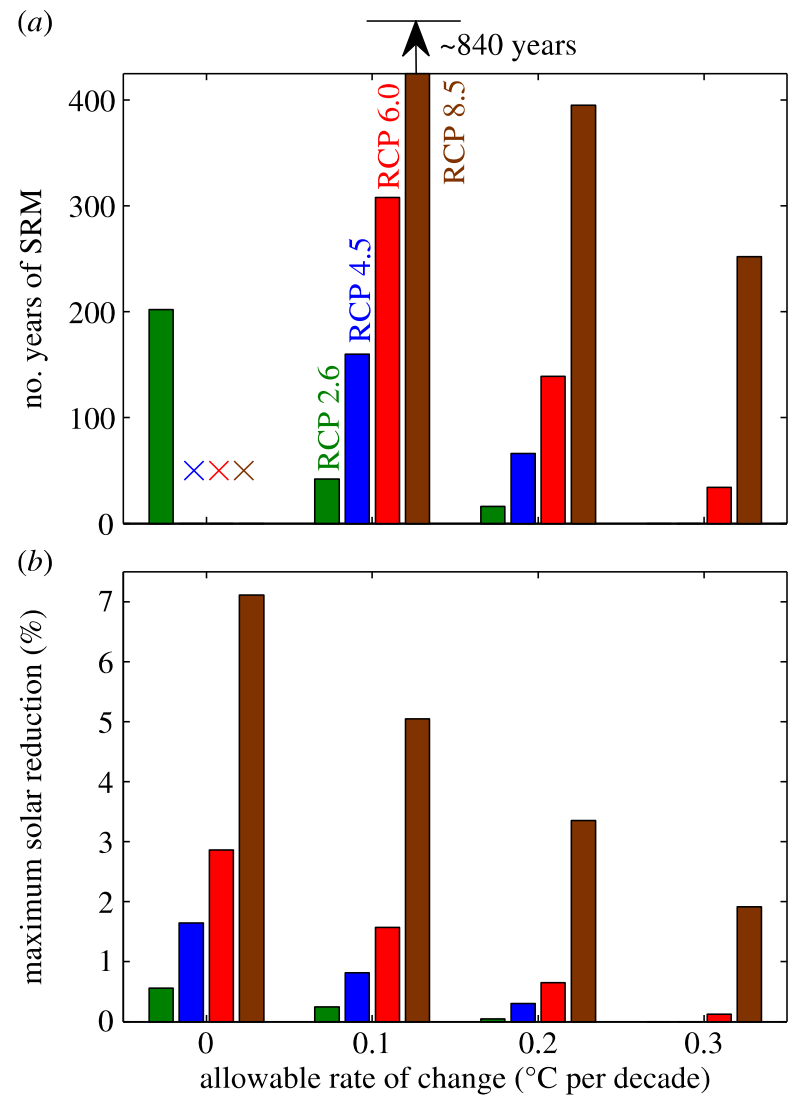

Figure 5. The top panel (a) shows the duration of SAI deployment and the below panel (b) shows the intensity of SAI that would be required to constrain the rate of temperature change for different RCP pathways. For RCP8.5, the amount and duration of SAI is significantly larger than for other pathways. If SAI (SRM) is used to maintain a constant temperature (zero rate of change), the maximum solar reduction is finite for each $\mathrm{RCP}$, but duration is only finite for RCP2.6 (indicated by ' $x$ ' for the other RCPs). (source: [38], online version in color.).

To summarize this section, there are plausible instantiations of BTA, fulfilling some of the stated requirements. One can refine and nuance such instantiations further on and perform scenario writing accordingly. Instantiations are indispensable as they shed new light on the requirements in detail.

\section{Requirements Revisited}

To recapitulate, the BT principle incorporates six crucial requirements:

1. The climate goal is indeed desirable (desirability);

2. Option O leads to desirable climate goal (effectiveness);

3. Option O only allows for finite $\mathrm{CE}$ deployment (temporariness, finitude, or exit strategy);

4. $\mathrm{CE}$ in $\mathrm{O}$ does not lead to less abatement compared to mitigation in $\mathrm{O}$ without $\mathrm{CE}$ (no-impediment thesis or "supplementary only");

5. There is no option $\mathrm{O}^{\prime}$ which is finite and which leads to the desired climate goal and which is better than $\mathrm{O}$ (no better option);

6. There are no general moral constraints to Option $\mathrm{O}$ (morality including governance).

We shall now discuss each of them in front of the deployment scenario introduced in the previous section. This provides a viable way to robustly evaluate any BTA in favor of SAI. 


\subsection{Desirability and Effectiveness}

According to the scenario set-up in the previous section, SAI will be successful in reducing the warming rate [38]. The authors argue that SAI will thus be able to reduce adaptation pressure, by buying more time for learning and installing different adaptation measures. Furthermore, if the RCP2.6 mitigation pathway is assumed, the stabilization of temperature at "well below $2{ }^{\circ} \mathrm{C}$ " above pre-industrial level is likely to be guaranteed. Therefore, indeed, SAI deployment can be called effective support if abatement comes close to RCP2.6. Strict abatement and temporary SAI are the supportive amendments-here again we have the BTA idea.

The second part of the effectiveness premise asks for a beneficial deployment. The weighting of the benefits and the negative side effects in order to guarantee some form of beneficial deployment, is a matter of dispute. It would be beyond the scope of this article to fully decide for the deployment scenarios at hand, if the benefits outweigh the costs. Whether the scenario at hand eventually is beneficial depends on model results we cannot judge. The question here is, if MacMartin's and Keith's deployment scenario has the theoretical conditions for the possibility of being beneficial. The beneficial requirement supposes some ideas about the beneficiaries on the one hand and about groups being put at risk by the side effects of SAI. This ratio between beneficiaries and disadvantages is to be determined and specified. Here, we enter thorny debates about the side effects of precipitation, delay of recovery of the ozone layer, acid rain, agricultural yields, migration, etc., as compared to the avoided loss and damage of climate change. Since both sides of the equation are more or less likely and speculative, the beneficial requirement remains empirically underdetermined. We leave it for further debate how BTA shall be judged if some crucial requirements remain underdetermined and speculative, resting on models.

For the sake of argument, there might be situations in which a BT deployment of SAI could be more beneficial than harmful. However, this might be only the case for low-scale SAI deployment, or far less or far shorter deployment than might be desirable from a purely temperature-based assessment. As the authors of this scenario state that, "Whatever the weighting of these benefits and cost functions, the ratio of benefits to costs will be largest for very small amounts of SRM" [39] (p. 204). They continue to observe that "(One) must conclude that the optimal amount of SRM will always be less than the amount of SRM that maximizes benefits" [39] (p. 204).

The authors rightly refer to the diminishing marginal utility of SAI deployment. The cost-benefit ratio of SAI deployment will be best for small amounts of SAI, which means that larger amounts will be uneconomical. This highly important conclusion should be present in any possible framing of SAI deployment. It implies that beneficial SAI deployment might be reasonable only within clear cut, very limited boundaries. Those boundaries might arguably be given in a RCP2.6 world, where emissions are cut to remain within the "well below $2{ }^{\circ} \mathrm{C}$ " budget and SAI would have to be deployed for a short period of time only. The fatal irony of BTA might be this: SAI might be legitimate only under conditions which render its deployment rather superfluous. Even then, there should be only a tiny bit of a dose. If so, a second look on costs for SAI research, testing, and deployment seems mandatory under the "least cost planning" approach.

One could oppose this line of thinking by taking a climate portfolio (option $\mathrm{O}$ ) into account, that also includes CDR measures, but applies to a different RCP scenario. If, for instance, in an RCP 6.0 scenario, pressure-reducing SAI is combined with concentration-shrinking CDR, SAI might well be allowed. The problem with this critique is this:

Emission cuts, when seen as a net-sum, can also be achieved via CDR or Negative Emission Technologies (NETs). Thus, a certain amount of emission reduction can be substituted with CDR (which makes an application of the BTA to CDRs more difficult than to SAI). Therefore, in theory, under RCP 6.0 CDR could be used to lower the net emissions to a degree somewhere between RCP 2.4 and RCP 4.5. The use of SAI in this case then would have to be judged against this new range, and not against RCP 6.0, since the $\mathrm{CO}_{2}$ concentration is decisive for duration and magnitude of SAI. Therefore, if CDR is used to reduce the net emissions to a reasonable degree, which SAI could 
safely and temporarily influence and thus making SAI deployment acceptable within the BTA—again, the deployment of SAI would be superfluous.

To summarize, the relationship between SAI and CDR in the BTA is not trivial. But the BTA cannot apply to CDR measures, because CDR is no peak shaving measure. An in-depth analysis of climate options that include both CDRs and SAI under different emission trajectories ought to be carried out, nevertheless.

\subsection{Finitude}

We see finitude as a practical concept resting upon assumptions about "timing" policies and controllability. Any timeframe that clearly surpasses the end of the century may, in theory, be finite, but cannot be handled practically. Additionally, it presents a huge risk transfer into the future. The decisive question of the BTA remains-“How long?"

In their 2014 paper, MacMartin at al. [38] determine the deployment time of SAI for different RCPs. In an RCP2.6 world SAI deployment would only be necessary for 40 years. However, the time frame increases sharply beyond RCP2.6. For RCP4.5, the duration of deployment would be 160 years, culmination to roughly 800 years for RCP8.5. Such long periods of time, or so we hold, are unacceptable, because they make SAI the usual business for at least four or six generations. Governance schemes cannot be guaranteed for 160 years, not to speak of 800 years. Thus, the risk of a sudden and, perhaps, involuntary termination remains, which clearly should not occur [40]. The longer SAI deployment, the more speculative "exit" strategies become. Finitude requirement demands and requires robust and non-trivial exit strategies for SAI based on BTA. Exit strategies must be planned in advance, must be carefully assessed, must be governed, etc.

If SAI looks permissible under a RCP2.6 trajectory only, it might not be needed at all, given prospects for adaptation and so-called "natural climate solutions" (NCS) in the realm of CDR, as reforestation, rewetting of mires, and carbon enrichment in soils. If so, under a RCP2.6 trajectory, the costs of research, testing, and deployment of short-term SAI must be compared to the option to invest in NCS and global adaptation financing schemes. This weighing follows the basic economic axiom that scarce means of production always have alternative options. Under a RCP2.6 trajectory, it remains an open question whether to invest, for example, USD 50 billion in SAI research and testing or in renewable energies, NCS, pro-poor adaptation, and decent resettlement programs. Asking for alternative options to invest scarce means also touches the question which societal groups are benefitted by SAI, respectively. It is political a question whether to produce butter or guns. This question becomes even more pressing for a post-COVID-19 economy. A very brief BT-based SAI under a RCP2.6 trajectory must be carefully checked in terms of opportunity costs, including the possibility of "sunk costs".

\subsection{No Impediment (Moral Hazard)}

As illustrated before, MacMartin and his colleagues contrast the SAI deployment with different RCPs. The RCPs and with them, mitigation efforts, are the background assumptions that enter their model set-up. Thus, the scenario design aligns with the requirement that SAI deployment should not compromise mitigation efforts.

The likelihood of this supposition is questionable. Even if the design of the scenario makes the no impediment thesis true, there is no guarantee that this will be the case if implemented in "real life" climate policy. The no-impediment-requirement points to the contested problem whether prospects for SAI may undermine abatement efforts ("moral hazard" or "trade-off", see [24,41]). Deliberative and participatory arrangements via so-called citizens' juries give evidence that lay persons rather display a negative trade-off [42]. As lay citizens are confronted with CE in general and with SAI in particular, they unanimously opt for aggressive abatement in order to avoid CE and, especially, SAI. Such findings, however, do not imply that decision makers will also adopt a negative trade-off. The empirical evidence on trade-off is uncertain at best. Thus, the no impediment requirement also remains underdetermined. Such underdetermination implies that there can be only partial fulfillment of 
given requirements. This is to say that perfect fulfillment is out of reach for BTA. If so, BTA-proponents must concede that partial fulfillment of requirements must suffice to legitimize SAI based on BTA.

\subsection{No Better Option}

The no better option thesis in our BT argument reconstruction works as a 'safeguard' to make sure that no option, not including SAI deployment, is ruled out prematurely. If two portfolios equally realize a desired climate goal, the portfolio without SAI should be adopted. Therefore, in context of this version of the BTA, it needs to be asked if there is a conceivable portfolio without SAI that is equally powerful in reducing the amount and rate of temperature change, in keeping climate change within a tolerable window of well below $2{ }^{\circ} \mathrm{C}$ and, thus, in reducing pressure for adaptation (narrowly understood).

As we have argued, SAI is specifically designed to influence the rate of change on basis of ambitious abatement strategies. It is an additional climate strategy that serves a secondary purpose. If there are other $\mathrm{CE}$ strategies that have similar additional benefits with fewer side effects, such alternatives (as NCS) must be evaluated carefully.

The no better option requirement looks as the strongest point in favor of SAI within the BTA approach. This points to the "lesser evil" argument. Originally, the "lesser evil" argument (LEA) had been designed as a comparative approach. It compared the evils of unmitigated climate change with the evils of CE and/or SAI. LEA, however, can be redesigned under the abatement requirement (LEA*). LEA* may take the following route: Even if the abatement requirement will be met, there will be many negative impacts (evils) within a specific period of time. Avoiding them by means of SAI turns out to be the lesser evil compared with a kind of painful period within a long abatement trajectory. LEA*, however, seems to collapse into the beneficence requirement which is uncertain.

\subsection{Moral Constraints and Governance Requirements}

As a matter of fact, only some of the more than 190 national states have the technological capacity to go for SAI. Perhaps only the U.S. is in a position to go for SAI. Other nations would be affected by its deployment for better or worse. We suppose an uneven, but uncertain distribution of effects. Since it is a large-scale manipulation of a global common good-the atmosphere-with uneven and uncertain effects, its deployment has to be subdued to common decision making among nations and states.

Fair governance schemes are essential for SAI deployment. Quite often, there are moral reasons for legal institutions and governance schemes. A sound moral principle is the "all affected principle" (AAP). If the impacts of a course of action affect many persons, groups, and nations ("parties"), and if there are side effects, uncertainties, double effects, concerns, etc., then all affected parties should have an equal voice in debates about the deontic status of such course of action (prohibition, allowance, obligation, rights). AAP is more demanding than the criterion of "multilateralism" which can be narrowly conceived in terms of a "coalition of the willing". AAP must be institutionalized. This AAP-based fair governance requirement must be determined by international law and by theories of international affairs. As one can learn from any textbook in international relations theories (IRT, see [43]), there is a plurality of schools in IRT. If one supposes neo-realism, international law is just a tool for making policies being ultimately grounded in presumed national interests [44,45]. Neo-realism would also allow to form a "coalition of the willing" and make use of gaps in international law since any legal position to SAI must be derived from international conventions and declarations serving other topics. Even under neo-realistic policies, there would be some governance regulating cooperation, patenting, contracting of companies, cost sharing, securitization, protection against counter $\mathrm{CE}$ and the like. The mere fact that there "is" some governance within a coalition of the willing, can, however, not meet the legitimacy requirement based on AAP.

Against neo-realism, we adopt a Rawlsian version of institutionalism in IRT. In the Rawlsian theory of global justice, some principles of international law are fixed [46]. If political representatives of particular people would opt for such principles, they would reasonably vote for a principle of equality 
among nations. Each national state has a right to be treated equally irrespectively of size of territory, military power, technological and financial capacities and the like. Under this anti-Hobbesian principle, no state is more equal than others. To Rawls, states are free to make voluntary treaties. Voluntariness implies to capability to give prior and informed consent. They also should assist peoples which suffer from unfavorable environmental living conditions. A nuanced dispute over the legitimacy criterion should ask, first, which principles should be applied to the SAI case. It should, second, give voice to the many states being affected by SAI. As long as there is no agreement given by, say, the general assembly of the United Nations, there should be a strict moratorium of SAI deployment since the legitimacy requirement has not been met. The SAI might be also a topic for the Security Council of UN. It seems fair to shift the burden of proof upon those who wish to water down the legitimacy requirement.

Our approach to governance is more demanding than Callies' conception of legitimacy [47]. From Buchanan, Callies adopts the Metacoordination View of institutional legitimacy and he applies it to the realm of international affairs. According to this approach, legitimacy comes and goes in degrees. There can be (very) weak kinds of legitimacy which are not fully just in substance or procedure. The concepts of justice and legitimacy are distinct. The only necessary criterion of legitimacy is "comparative benefit". This criterion compares governance schemes either to the non-institutional alternative or to an institutional alternative. Buchanan and Callies suppose that, in international affairs, some kind of governance is, in principle, superior to the non-institutional alternative. Therefore, the necessary condition is easy to fulfill, if there is no viable institutional alternative to governance. Callies identifies four other normative criteria beside comparative benefit: accountability, transparency, substantive justice, and procedural justice. These criteria must be specified to "substantive standards" according to different interpretation regarding normative content. Callies concedes that "nailing down normative criteria for legitimacy assessments is difficult", if the competences and powers of governance schemes remain unclear. The metacoordination approach to legitimacy may stimulate further debate, but it does not refute the claim that voluntary and well-informed consent of all parties being affected by SRM should be decisive in all governance schemes. Why should a Rawlsian-Habermasian conception of legitimacy "not apply to international institutions very well" [47] (p. 326)? The statement that international institutions, in fact, exercise power without consent does not provide any normative reason why the criterion of informed consent should not play an important role in the set of criteria which legitimate SRM governance schemes should fulfill.

A global moratorium on SAI deployment might be hard to achieve, but at least it could be argued that common global agreements are possible and are, in fact, presently installed in many different areas. A moratorium, however, would affect SAI in terms of costs. SAI prospects being based on BTA recognizing requirements are allowed to do some research well below the threshold of large fields trials, but have to recognize the normative gap between research and deployment. If so, research might be finally in vain ("sunk costs"). Presumably "sunk-cost" research (as an instance of stranded assets) is not a purely scientific affair. It is political economy of SAI research. May a state ramp up SAI facilities by way of large-scale research and strictly conform to a Rawlsian interpretation of how to determine the legitimacy requirement? Ott [5] has cast some doubts upon this question mark. If bars are set high, BT-based SAI cannot meet the governance requirement.

There might be other moral constraints of BT-based SAI. One general moral argument against the deployment of SAI has been brought forward from the viewpoint of virtue ethics. The hubris argument states that we should not engage in any SRM scheme, for the scope of the endeavor is just beyond our human understanding and control. Trying to control the climate system, even for a limited period of time, would be a sign of hubris, in that it ignores the role humans can and should play on this planet. The hubris argument has been one of the earliest virtue ethical arguments against the deployment of CE in general [48-51].

A common perception of the hubris framing is that man should not aim at interfering with a given natural order. Such metaphysical version of the hubris argument lacks an essential deductive step from any sort of metaphysical order to the fact that we as humans need to respect it [52]. Non-metaphysical 
concepts of hubris argue that persons (or groups) show hubris, if they act out of "reprehensible overestimation of their abilities" [53] (p. 5). Hubris as defined by Meyer and Uhle [53] is connected to epistemic virtues of what we can possibly know and control. Hubris ought to be avoided because it involves a failure and a vice: The failure lies in the misjudgment of the probability of CE research results, the vice lies in the recklessness of advocating controllability of $C E$ despite the epistemic failure. Such post-metaphysical hubris argument warns against the common attitude of overrating capacities to solve any problem whatsoever by the devices of modernity: science, technology, power, capital, and human ingenuity (see also [54]). Such warning can be directed also against mindsets resulting from modelling. The attitude against hubris is a deep concern that the promise of science and technology and, perhaps, the daily epistemic practice of modelling as such entails moral corruption based on overrating [55]. The hubris argument can be re-formulated as a prudent risk-aversive virtue ethical argument holding under conditions of uncertainty. It forces us to weigh uncertainty in a specific way. In this sense, the hubris argument serves as a meta-argumentative guideline about the status of arguments, in that it weighs the argument about irreducible uncertainty stronger than other arguments.

While the hubris argument has moral force in evaluating SAI deployment, it might arguably be met by a careful and modest deployment scheme. Consequently, [38] include a learning curve and require SAI deployment to be responsive, so that new information can lead to a modification or even the decline of SAI deployment.

The hubris argument comes in full force, if some essential requirements of the BTA remain underdetermined. If requirements can be met partially at best, the hubris argument may play the role of a "tie breaker" - better not, all things considered.

However, especially in light of sufficient mitigation, a buying time deployment can be justified. BTA addresses the secondary climate goal of reducing pressure. Arguably, reducing the pressure for mitigation only then makes sense, when mitigation is indeed undertaken. Paradoxically, it might not be valid to reject $C E$ deployment in face of sufficient mitigation.

\section{Summary, Conclusions, Suggestion}

Let us sum up our entire reflective argument on BT-based permissibility of SAI. If criticism against the emergency argument is accepted (as we do), BTA is the "last man standing" in favor of SAI. The BTA has some initial moral ("humanitarian") force and it can be instantiated with models and scenarios. If BTA, however, fails, SAI has lost moral grounds completely. We summarize our main findings in order to judge upon the if-clause.

BTA is both a peak-shaving and a reducing-pressure strategy. It addresses both primary and secondary climate goals. BTA as a peak-shaving proposal refers in a morally decent way to a conditional and imperfect second-best solution with contestable side effects. BTA-based SAI might be helpful in terms of adaptation, either broadly or narrowly conceived. SAI might also be calculated within an overall "least cost planning" model. The strongest version of BTA would be both humanitarian with respect to vulnerable groups ("peak-shaving") and effective with respect to reducing opportunity costs of a long process of decarbonization ("least cost planning"). This version might be strong enough to shift the argumentative burden upon opponents who may further on argue with uncertain side effects, missing governance etc. Since the arguments on the contra-side are contested as well [56], BTA-based SAI does not look completely impermissible.

Such buying time deployment of SAI, however, must be able to meet some requirements. We tried to identify crucial requirements in the previous sections and discussed them in some detail. Those are:

- $\quad \mathrm{SAI}$ is conditional upon ambitious abatement;

- It is just an amendment, not a substitute;

- $\quad$ SAI must be finite;

- $\quad$ SAI must not fall to general moral constraints and must be apt for just governance. 
The conditional of complementarity to abatement removes all cost estimates showing that SAI is cheaper than abatement. In addition to abatement, things look differently. Moreover, there is legitimate distrust in nations which do not contribute to global abatement policies but start research on SAI, because they may see SAI as imperfect substitute for abatement.

Whether those requirements can be met remains empirically underdetermined. We trust that the predictive capabilities of models are more than prophecy, yet large uncertainty prevails (see [57,58]).

We cast doubts on whether the requirements of fair global governance can be met. Concerns about hubris also remain. The hubris argument comes in full force, if some essential requirements of the BTA remain underdetermined-as they do! A non-metaphysical hubris argument might be conjoined with concerns about moral hazards, hazardous side effects, and uncertain exit options.

Holly Buck [9] is rightly pointing at the time of ecological restoration hopefully following climate engineering. It seems desirable that this time should come as soon as possible. If so, the requirement of finitude of SAI seems crucial. Time spans of hundreds of years are unpredictable and unacceptable. Proponents of BTA concede that SAI should be minimized in terms of duration and magnitude of Sulphur. Minimizing SAI deployment under the conditional of complementarity to abatement and with realistic assessment of full costs may result in recognizing that SAI is not just risky, but also highly expensive. An analogy to nuclear energy might be at place.

If one combines BTA with outlooks for an ecological civilization after geoengineering [9], one must take into accounts whether SAI technologies are neutral with respect to such transition. Technologies are not neutral, and climate technologies especially must be shaped in accordance with a sustainable future [59]. SAI research, testing, and deployment over some decades must not involve path dependencies against the modes of societal and cultural change we ultimately wish to see. This is a non-trivial assumption. Gunderson et al. [54], Ott [5], Surprise [16] have argued that SAI is a large-scale scientific, technological, industrial, and even military complex, not just a simple neutral technological mean (like a hammer or a knife). It remains questionable whether a global society can ramp up such complex and perform an ecological transformation in parallel.

The fatal irony of BTA might be this: SAI might be permissible only under conditions which render its deployment rather superfluous, risky, and costly. Minimized and finite SAI must be compared to prospects of maximized NCS, augmenting abatement. Such comparison looks promising to us and might be the topic of further inquiry.

Finally, one can distinguish between perfect and partial fulfillment of such requirements. If perfect fulfillment of conditionals may permit SAI, the case is less clear in case of partial fulfillment which is more likely. We may think of a range between perfect fulfillment and some "red" threshold line of partiality below which SAI is forbidden. But where to draw such line? There might be a slippery slope-While the SAI technological complex is ramped up, it becomes evident that the conditionals will not be met perfectly. Which course of action, then, will be more likely: Stopping SAI or keeping $\mathrm{SAI}$ in the range of permissibility by watering down the threshold line of "minimal" requirements?

A rather clear-cut alternative to such shifting threshold line is this: If requirements can be met partially at best, the hubris argument should play the role of a "tie breaker" — better not, all things considered. Under this alternative, the deontic flashlight turns to red. Then, the "last man standing" has fallen. We wish to conclude with presenting this alternative to further debate.

Author Contributions: Writing-original draft, F.N. and K.O. All authors have read and agreed to the published version of the manuscript.

Funding: This research was funded by DFG SPP 1689: Climate Engineering-Risks, Challenges, Opportunities? Conflicts of Interest: The authors declare no conflict of interest. 


\section{References}

1. Betz, G.; Cacean, S. Ethical Aspects of Climate Engineering; KIT Scientific Publishing: Karlsruhe, Germany, 2012.

2. Ott, K. Klimaflüchtlinge': Zur Komplexität der Begriffsbildung. In Der Begriff des Flüchtlings; Kersting, D., Leuoth, M., Eds.; Metzler: Stuttgart, Germany, 2020; pp. 157-177. Available online: https://publikationen. bibliothek.kit.edu/1000084294 (accessed on 2 July 2020).

3. Neuber, F. Buying Time with Climate Engineering? An Analysis of the Buying Time Framing in favor of Climate Engineering; KIT Scientific Publishing: Karlsruhe, Germany, 2018.

4. Baatz, C.; Ott, K. Why Aggressive Mitigation Must Be Part of Any Pathway. In Justice and Geoengineering; Preston, C., Ed.; Rowman \& Littlefield: Lanham, MD, USA, 2016; pp. 93-108.

5. Ott, K. On the Political Economy of Solar Radiation Management. Front. Environ. Sci. 2018, 6. [CrossRef]

6. Ott, K.; Neuber, F. Climate Engineering. In Oxford Research Encyclopedias: Climate Science; Oxford University Press: Oxford, UK, 2020.

7. Weinberg, A. Can Technology Replace Social Engineering? In Controlling Technology: Contemporary Issues; Katz, E., Light, A., Thompson, W., Eds.; Prometheus books: Buffalo, NY, USA, 1991; pp. 41-48.

8. Steffen, W.; Rockström, J.; Richardson, K.; Lenton, T.M.; Folke, C.; Barnosky, A.D.; Cornell, S.E.; Crucifix, M.; Donges, J.F.; Fetzer, I.; et al. Trajectories of the Earth System in the Anthropocene. Proc. Natl. Acad. Sci. USA 2018, 33, 8252-8259. [CrossRef] [PubMed]

9. Buck, H. After Geoengineering; Verso: London, UK; New York, NY, USA, 2019.

10. Buck, H.J.; Martin, L.J.; Geden, O.; Kareiva, P.; Koslov, L.; Krantz, W.; Kravitz, B.; Noël, J.; Parson, E.A.; Preston, C.J.; et al. Evaluating the efficacy and equity of environmental stopgap measures. Nat. Sustain. 2020. [CrossRef]

11. Royal Society. Solar Radiation Management: The Governance of Research; The Royal Society of London: London, UK, 2011. Available online: https://royalsociety.org/ \{\}/media/Royal_Society_Content/policy/projects/solarradiation-governance/DES2391_SRMGI\%20report_web.pdf (accessed on 2 July 2020).

12. Huttunen, S.; Hildén, M. Framing the Controversial: Geoengineering in Academic Literature. Sci. Commun. 2013, 36, 3-29. [CrossRef]

13. Sillmann, J.; Lenton, T.M.; Levermann, A.; Ott, K.; Hulme, M.; Benduhn, F.; Horton, J.B. Climate emergencies do not justify engineering the climate. Nat. Clim. Chang. 2015, 5, 290-292. [CrossRef]

14. Horton, J. The emergency framing of solar geoengineering: Time for a different approach. Anthr. Rev. 2015, 2, 1-5. [CrossRef]

15. Schmitt, C. Political Theology; University of Chicago Press: Chicago, IL, USA, 2006; (Original 1922).

16. Surprise, K. Geopolitical ecology of solar geoengineering: From a 'logic of multilateralism' to logics of militarization. J. Political Ecol. 2020, 27, 213-235. [CrossRef]

17. Chaelecki, E.L.; Ferrari, L.L. A New Security Framework for Geoengineering. Strateg. Stud. Q. 2018, 12, 82-106.

18. Schäfer, S.; Maas, A.; Stelzer, H.; Lawrence, M.G. Earth's future in the Anthropocene: Technological interventions between piecemeal and utopian social engineering. Earth's Future 2014, 2, 239-243.

19. MacCracken, M. On the possible use of geoengineering to moderate specific climate change impacts. Environ. Res. Lett. 2009, 4, 045107. [CrossRef]

20. Lenton, T.; Vaugham, N. (Eds.) Geoengineering Responses to Climate Change. In Selected Entries from the Encyclopedia of Sustainability Science and Technology; Springer: New York, NY, USA; Heidelberg, Germany; Dordrecht, The Netherlands; London, UK, 2013.

21. Rayner, S.; Heyward, S.; Kruger, T.; Pidgeon, N.; Redgwell, C.; Savulescu, J. The Oxford Principles. Clim. Chang. 2013, 121, 499-512. [CrossRef]

22. Hintikka, J. Knowledge and Belief; Cornell University Press: Ithaca, NY, USA, 1962.

23. Brandom, R. Making It Explicit; Harvard University Press: Cambridge, MA, USA, 1994.

24. Baatz, C. Can we have it both ways? On potential trade-offs between Mitigation and Solar Radiation Management. Environ. Values 2016, 25, 29-49. [CrossRef]

25. Bunzl, M. Researching geoengineering: Should not or could not? Environ. Res. Lett. 2009, 4, 045104. [CrossRef] 
26. MacDougall, A.H.; Frölicher, T.L.; Jones, C.D.; Rogelj, J.; Matthews, H.D.; Zickfeld, K.; Arora, V.K.; Barrett, N.J.; Brovkin, V.; Burger, F.A.; et al. Is there warming in the pipeline? A multi-model analysis of the Zero Emissions Commitment from $\mathrm{CO}_{2}$. Biogeosciences 2020, 17, 2987-3016. [CrossRef]

27. Keith, D. A Case for Climate Engineering; Boston Review Books: Boston, MA, USA, 2013.

28. Zürn, M.; Schäfer, S. The Paradox of Climate Engineering. Glob. Policy 2013, 4, 223-324. [CrossRef]

29. Wigley, T.M. A combined mitigation/geoengineering approach to climate stabilization. Science 2006, 314, 452-454. [CrossRef]

30. Parson, E.; Ernst, L. International Governance of Climate Engineering. Theor. Inq. Law 2013, 14, 307-337. [CrossRef]

31. Barrett, S. The incredible economics of geoengineering. Environ. Resour. Econ. 2008, 39, 45-54. [CrossRef]

32. Ott, K. Domains of Climate Ethics. Jahrb. Wiss. Ethik 2014, 16, 95-114. [CrossRef]

33. Hampicke, U. Climate change economics and discounted utilitarianism. Ecol. Econ. 2011, 72, 45-52. [CrossRef]

34. Klepper, G.; Rickels, W. The real economics of climate engineering. Econ. Res. Int. 2012, 56, 1-20. [CrossRef]

35. Aaheim, A.; Romstad, B.; Wie, T.; Kristjansson, J.E.; Muri, H.; Niemeier, U.; Schmidt, H. An economic evaluation of solar radiation management. Sci. Total Environ. 2015, 532, 61-69. [CrossRef] [PubMed]

36. Morrow, D.R. Ethical aspects of the mitigation obstruction argument against climate engineering research. Philos. Trans. R. Soc. A 2014, 37220140062. [CrossRef] [PubMed]

37. Lockley, A.; Xu, Y.; Times, S. Politically relevant geoengineering scenarios. ESSOAr 2020. (Manuscript posted online 22 April 2020, submitted to Earth's Future). [CrossRef]

38. MacMartin, D.G.; Caldeira, K.; Keith, D.W. Solar geoengineering to limit the rate of temperature change. Philos. Trans. R. Soc. A 2014, 372, 20140134. [CrossRef] [PubMed]

39. Keith, D.; MacMartin, D. A temporary, moderate and responsive scenario for solar geoengineering. Nat. Clim. Chang. 2015, 5, 201-206. [CrossRef]

40. Ott, K. Might Solar Radiation Management Constitute a Dilemma? In Engineering the Climate. The Ethics of Solar Radiation Management; Preston, C., Ed.; Lexington: Lanham, MD, USA, 2012; pp. 33-42.

41. Lin, A. Does Geoengineering Present a Moral Hazard. Ecol. Law Q. 2013, 673, 672-712.

42. Merk, C.; Klaus, G.; Pohlers, J.; Ernst, A.; Ott, K.; Rehdanz, K. Public perceptions of climate engineering. Gaia 2019, 28, 348-355. [CrossRef]

43. Dunn, T.; Kurki, M.; Smith, S. (Eds.) International Relations Theory; Oxford University Press: Oxford, UK, 2013; pp. 59-76.

44. Lebow, R. Classical Realism. In International Relations Theory; Dunn, T., Kurki, M., Smith, S., Eds.; Oxford University Press: Oxford, UK, 2013; pp. 59-76.

45. Mearsheimer, J. Structural Realism. In International Relations Theory; Dunn, T., Kurki, M., Smith, S., Eds.; Oxford University Press: Oxford, UK, 2013; pp. 77-93.

46. Rawls, J. The Law of Peoples; Harvard University Press: Cambridge, MA, USA, 1999.

47. Callies, D.E. Institutional Legitimacy and Geoengineering Governance. Ethics Policy Environ. 2018, 21, 324-340. [CrossRef]

48. Jamieson, D. Ethics and Intentional Climate Change. Clim. Chang. 1996, 33, 323-336. [CrossRef]

49. Ott, K. Argumente für und wider "Climate Engineering". Versuch einer Kartierung. Tech. Theor. Prax. 2010, 19, 32-41.

50. Gardiner, S. Is 'Arming the Future' with Geoengineering Really the Lesser Evil? Some Doubts about the Ethics of Intentionally Manipulating the Climate System. In Climate Ethics: Essential Readings; Gardiner, S., Caney, S., Jamieson, D., Shue, H., Eds.; Oxford University Press: Oxford, UK, 2010; pp. 284-312.

51. Owen, R. Solar Radiation Management and the Governance of Hubris. Issues Environ. Sci. Technol. 2014, 38, 212-248.

52. Levine, G.L. Has It Really Come to This? An Assessment of Virtue Ethical Approaches to Climate Engineering. Bachelor's Thesis, Yale University, New Haven, CT, USA, 2014. Available online: http: //politicalscience.yale.edu/sites/default/files/files/Levine_Gabriel.pdf (accessed on 2 July 2020).

53. Meyer, K.; Uhle, C. Geoengineering and the Accusation of Hubris; THESys Discussion Paper No. 2015-3; Humboldt-Universität zu Berlin: Berlin, Germany, 2015; Available online: edoc.hu-berlin.de/series/ thesysdiscpapers (accessed on 2 July 2020).

54. Gunderson, R.; Petersen, B.; Stuart, D. A Critical Examination of Geoengineering: Economic and Technological Rationality in Social Context. Sustainability 2018, 10, 269. [CrossRef]

55. Jonas, H. Das Prinzip Verantwortung; Insel: Frankfurt, DE, USA, 1979. 
56. Reynolds, J.; Parker, A.; Irvine, P. Five solar geoengineering tropes that have outstayed their welcome. Earth's Future 2016, 4, 562-568. [CrossRef]

57. Riahi, K.; van Vuuren, D.P.; Kriegler, E.; Edmonds, J.; Oneill, B.C.; Fujimori, S.; Bauer, N.; Calvin, K.; Dellink, R.; Fricko, O.; et al. The Shared Socioeconomic Pathways and their energy, land use, and greenhouse gas emissions implications: An overview. Glob. Environ. Chang. 2017, 42, 153-168. [CrossRef]

58. Oneill, B.C.; Kriegler, E.; Ebi, K.L.; Kempbenedict, E.; Riahi, K.; Rothman, D.S.; van Ruijven, B.J.; van Vuuren, D.P.; Birkmann, J.; Kok, K.; et al. The roads ahead: Narratives for shared socioeconomic pathways describing world futures in the 21st century. Glob. Environ. Chang. 2017, 42, 169-180. [CrossRef]

59. Muraca, B.; Neuber, F. Viable and convivial technologies. Considerations on Climate Engineering from a degrowth perspective. J. Clean. Prod. 2017, 197, 1810-1822. [CrossRef]

(C) 2020 by the authors. Licensee MDPI, Basel, Switzerland. This article is an open access article distributed under the terms and conditions of the Creative Commons Attribution (CC BY) license (http://creativecommons.org/licenses/by/4.0/). 